\title{
Espaço do Ensino na Formação Docente
}

\author{
Espacio de la Enseñanza en la Formación Docente
}

Space Of Teach In Teacher Education

Fabricio Medeiros Ayres ${ }^{1}$

Luana Maria Santos da Silva Ayres ${ }^{2}$

\begin{abstract}
Resumo
O sistema de ensino enfrenta diversos problemas quanto ao seu desempenho, seja pelo grande número de abandonos, reprovações ou mesmo pelas aprovações na qual os alunos não aprendem o mínimo esperado. Logo, percebe-se que a formação inicial de professores pode desempenhar um papel preponderante nesta mudança, e que o ensinar a ensinar é parte importante na fundamentação teórica desta formação. Por esse motivo este trabalho tem o objetivo de investigar as publicações que abordem como as teorias de ensino estão sendo trabalhadas em cursos de licenciaturas em universidades públicas do Brasil. Para tanto, realizou-se uma busca, na Scielo, que não recuperou artigos, e no Google Acadêmico que recuperou 74 artigos. Em ambas as buscas foram utilizada a expressão: "teorias de ensino" AND "curso de licenciatura" AND "universidade pública". Após refinamento da busca, foram selecionados seis artigos, que posteriormente foram analisados através da Análise de Conteúdo. Da análise emergiram duas categorias: Espaço do ensino nos currículos de licenciatura, que aborda o ensino das disciplinas de didática e psicologia da educação em universidades; e Formação de professores, que aborda a formação de professores em diferentes licenciaturas. Através desse estudo, conclui-se que, apesar da importância do tema, há uma carência de publicações que tratem sobre as teorias de ensino nos cursos de licenciatura.
\end{abstract}

Palavras-Chave: Ensino; Formação docente; Licenciatura

\section{Resumen}

El sistema de enseñanza enfrenta diversos problemas en cuanto a su desempeño, ya sea por el gran número de abandonos, reprobaciones o incluso por las aprobaciones en que los alumnos no aprenden el mínimo esperado. Luego, se percibe que la formación inicial de profesores puede desempeñar un papel preponderante en este cambio, y que el enseñar a enseñar es parte importante en la fundamentación teórica de esta formación. Por este motivo este trabajo tiene el objetivo de investigar las publicaciones que aborden cómo las teorías de enseñanza están siendo trabajadas en cursos de licenciaturas en universidades públicas de Brasil. Para ello, se realizó una búsqueda, en Scielo, que no recuperó artículos, y en el Google Académico que recuperó 74 artículos. En ambas búsquedas se utilizó la expresión: "teorias de ensino" AND "curso de licenciatura" AND "universidade pública". Después de refinamiento de la búsqueda, fueron seleccionados seis artículos, que posteriormente fueron analizados a través del Análisis de Contenido. En el análisis surgieron dos categorías: Espacio de la enseñanza en los currículos de licenciatura, que aborda la enseñanza de las disciplinas de didáctica y psicología de la educación en universidades; y Formación de profesores, que aborda la formación de profesores en diferentes licenciaturas. A través de este estudio, se concluye que, a pesar de la importancia del tema, hay una carencia de publicaciones que traten sobre las teorías de enseñanza en los cursos de licenciatura.

Palabras claves: Enseñanza; Formación docente; Licenciatura

\footnotetext{
${ }^{1}$ Especialista em Serviço Social, Psicólogo, Universidade Federal do Rio Grande - FURG, Rio Grande, Rio Grande do Sul, Brasil, fabricio_ayres@outlook.com

${ }^{2}$ Mestranda do Programa de Pós-graduação em Educação em Ciência, Universidade Federal do Rio Grande FURG, Rio Grande, Rio Grande do Sul, Brasil, luana_ayres@furg.br
} 


\begin{abstract}
The education system faces several problems regarding its performance, either by the great number of dropouts, reprobation or even by the approvals in which the students do not learn the expected minimum. Therefore, it can be seen that the initial formation of teachers can play a major role in this change, and that teach teaching is an important part of the theoretical foundation of this formation. For this reason, this work has the objective of investigating publications that address how teaching theories are being studied in education degree in public universities in Brazil. For that, a search was made, in Scielo, that did not retrieve articles, and in Google Scholar that recovered 74 articles. In both searches we used the expression "teorias de ensino" AND "licenciaturas" AND "univercidade pública". After refinement of the search, six articles were selected, which were later analyzed through Content Analysis. From the analysis emerged two categories: Space of the teach in the teaching degree curriculum, that approaches the teaching of the disciplines of didactics and psychology of the education in universities; and teacher training, which addresses the training of teachers in different degrees. Through this study, it is concluded that, despite the importance of the subject, there is a lack of publications that deal with teaching theories in undergraduate courses.
\end{abstract}

Keywords: Teaching; Teacher training; Education degree

\title{
1. Introdução
}

É de conhecimento comum que o Sistema Educacional brasileiro enfrenta dificuldades. Porém, quando verifica-se os números apresentados pelo Instituto Nacional de Estudos e Pesquisas Educacionais Anísio Teixeira (INEP), resultantes das avaliações externas aplicadas no ano de 2017 (FUNDAÇÃO LEMANN; MERITT, 2018), conseguimos ter uma real noção do tamanho do problema. Além do número baixo de alunos que obtiveram um desempenho mínimo adequado para o seu estágio escolar, também existe um alto índice de evasão e repetência.

De acordo com o Índice de Desenvolvimento da Educação Básica (IDEB), que tem seus dados calculados levando em consideração dois indicadores: fluxo escolar e o desempenho nas avaliações externas (INEP, 2015), há um crescimento, mesmo que lento, nos índices apresentados no ensino fundamental, havendo uma estagnação no ensino médio quando comparamos os dados de 2015 e 2017. Porém, desde 2011 que os anos finais do ensino fundamental e o ensino médio não atingem a meta estipulada.

Pode-se ter uma noção melhor do estado crítico da educação quando são analisados os dados referente a porcentagem de alunos que aprenderam o adequado em leitura e interpretação de texto, ou ainda pior, em resolução de problemas matemáticos. De acordo com os dados apresentados pelo INEP (2015), 50\% dos alunos do $5^{\circ}$ ano aprenderam o adequado para esta etapa no que se refere a leitura e interpretação de textos. Esta porcentagem diminui para $30 \%$ quando são avaliados os alunos do $9^{\circ}$ ano.

Se estes números são motivo de espanto e temor, a situação piora quando são avaliados a respeito da resolução de problemas matemáticos. De acordo com o INEP (2015), 
dos 2.438.249 alunos do $5^{\circ}$ ano avaliados, 39\% obtiveram desempenho satisfatório. Porcentagem esta, que cai para 14\% de 2.097.630 quando são avaliados alunos do $9^{\circ}$ ano.

Pode-se desta forma afirmar, com base nos números apresentados, que o sistema de ensino brasileiro está em uma situação precária, precisando de medidas urgentes para que este cenário seja modificado.

São imensuráveis os prejuízos acarretados pela baixa qualidade da educação brasileira. É claro que este o problema não é uma equação simples de se resolver, existem diversos fatores envolvidos na aprendizagem do aluno, tais como a estrutura escolar, professores, colegas, contexto social e familiar. Todavia, o que pode propiciar instrumentos de análise que permitam identificar estes fatores? Assim como, de que modo eles contribuem para que este cenário se estabeleça? O que é possível modificar neste sistema? O que está ao alcance da população escolar e dos pesquisadores?

Por acreditar que a formação inicial do docente pode ter papel fundamental nesta mudança. Mais especificamente, que o domínio das teorias do ensino e da aprendizagem podem instrumentalizar o professor para que ele possa ser capaz de ter consciência das variáveis que estão presentes nestes processos. Essa escrita tem como objetivo investigar as publicações que abordem como as teorias de ensino estão sendo trabalhadas em cursos de licenciaturas em universidades públicas do Brasil. Para tanto realizou-se uma triagem de artigos no Google acadêmico e na Scielo, após refinamento dos dados selecionou-se seis artigos que através da técnica de Análise de Conteúdo compuseram duas categorias: Espaços do ensino no currículo dos cursos de licenciatura e Formação de professores.

\section{Metodologia}

Para a elaboração desta escrita realizou-se um mapeamento de artigos no Google Acadêmico e na Scielo, com a finalidade de encontrar artigos que abordassem como estão sendo trabalhadas as teorias de ensino nos cursos de licenciaturas. Para tanto utilizou-se como palavras-chaves "cursos de licenciatura", "universidade pública" e "teorias de ensino", salienta-se que utilizou-se aspas e o conectivo $A N D$, ou seja, os artigos deveriam conter todas essas três palavras-chaves. Ao final dessa seleção, encontrou-se 74 artigos, posteriormente foi realizada a leitura dos resumos, sendo selecionados seis, conforme fica ilustrado no Quadro 1. 
RELACult - Revista Latino-Americana de Estudos em Cultura e Sociedade

Quadro 1 - Artigos Selecionados

\begin{tabular}{|c|c|c|c|c|}
\hline ARTIGO & TÍTULO & AUTOR & ANO & REVISTA \\
\hline A1 & $\begin{array}{l}\text { Ensino de didática: um estudo sobre } \\
\text { concepções e práticas de professores } \\
\text { formadores }\end{array}$ & $\begin{array}{l}\text { CRUZ, Giseli Barreto da; } \\
\text { ANDRE, Marli Eliza } \\
\text { Dalmazo Afonso de. }\end{array}$ & 2014 & Educação em Revista \\
\hline A 2 & $\begin{array}{l}\text { O ensino de didática em cursos de } \\
\text { licenciatura na perspectiva do professor } \\
\text { formador }\end{array}$ & $\begin{array}{l}\text { CRUZ, Giseli Barreto da; } \\
\text { BORGES, Luis Paulo da } \\
\text { Cruz }\end{array}$ & 2012 & $\begin{array}{l}\text { XVI ENDIPE - } \\
\text { Encontro Nacional de } \\
\text { Didática e Práticas de } \\
\text { Ensino }\end{array}$ \\
\hline A3 & $\begin{array}{l}\text { Reflexões e desafios } \\
\text { professores de língu }\end{array}$ & $\begin{array}{l}\text { ARAÚJO, Marcus de } \\
\text { Souza }\end{array}$ & 2016 & $\begin{array}{l}\text { Revista L@el em } \\
\text { (Dis-)curso }\end{array}$ \\
\hline A4 & $\begin{array}{l}\text { Psicologia educacional: concepções de } \\
\text { professores de curso de licenciatura }\end{array}$ & $\begin{array}{l}\text { RODRIGUES, Maria } \\
\text { Ester }\end{array}$ & 2016 & $\begin{array}{l}\text { Psicologia da } \\
\text { Educação }\end{array}$ \\
\hline A5 & $\begin{array}{l}\text { A formação pedagógica no curso de } \\
\text { licenciatura em física: articulação entre } \\
\text { os campos do conhecimento }\end{array}$ & $\begin{array}{l}\text { ROMANOWSKI, Joana } \\
\text { Paulin; SILVA, Priscila } \\
\text { Juliana Da }\end{array}$ & 2018 & Revista Ensaio \\
\hline A6 & $\begin{array}{l}\text { Os dizeres dos alunos de um curso de } \\
\text { licenciatura em matemática }\end{array}$ & $\begin{array}{l}\text { VERONEZ, Michele } \\
\text { Regiane Dias; PEREIRA, } \\
\text { Emanueli }\end{array}$ & 2017 & $\begin{array}{l}\text { Educação Matemática } \\
\text { em Revista }\end{array}$ \\
\hline
\end{tabular}

Fonte: Os autores

Conforme pode-se observar na tabela acima, os artigos selecionados nesta pesquisa foram publicados entre 2012 e 2018 , sendo que a busca nos portais foi realizada em setembro de 2018, deste modo ainda poderá haver trabalhos que serão publicados no ano de 2018 que não estão contemplados nesta pesquisa. Posteriormente realizou-se uma análise qualitativa dos seis artigos selecionados.

\section{Análise dos dados}

Os artigos selecionados nessa pesquisa formaram duas categorias de estudo através da técnica de Análise de Conteúdo de Bardin (2011). Esta técnica é constituída de "[...] um conjunto de técnicas de análise de comunicações que utiliza de procedimentos sistemáticos e objetivos de descrição do conteúdo das mensagens" (BARDIN, 2011, p. 45). Primeiramente realizou-se uma pré-análise para sistematizar as ideias centrais dos sete artigos. A partir dessa pré-análise classificou-se os artigos em unidades de registro e unidades de contexto com a finalidade de obter categorias. As unidades de registro são unidades que correspondem a um segmento do texto que por meio de recortes podem expressar um tema. Por sua vez, as unidades de contexto, que são expressas por uma temática "[...] são ótimas para que possa compreender uma significação exata da unidade de registro" (BARDIN, 2011, p. 137). Posteriormente realizou-se a categorização destas unidades como fica evidente no Quadro 2. 
Quadro 2: Unidades de contexto e categorias

\begin{tabular}{|l|c|}
\hline \multicolumn{1}{|c|}{ UNIDADES DE CONTEXTO } & CATEGORIAS \\
\hline O ensino de didática em universidades & $\begin{array}{c}\text { Espaço do ensino nos currículos de } \\
\text { licenciatura }\end{array}$ \\
\hline Psicologia educacional e escolar & Formação de professores \\
\hline Composição curricular do curso de Física & \\
\hline A constituição do professor & \\
\hline Curso de Licenciatura em Letras & \\
\hline
\end{tabular}

Dessas duas categorias que emergiram da análise, a primeira refere-se ao ensino das disciplinas de didática e psicologia da educação em universidades; e a segunda aborda a formação de professores em diferentes licenciaturas. No Quadro 3, é evidenciado o número de artigos que compõe cada categoria.

Quadro 3: Número de artigos por categorias

\begin{tabular}{|l|c|}
\hline \multicolumn{1}{|c|}{ CATEGORIAS } & NÚMERO DE ARTIGOS \\
\hline Espaço do ensino nos currículos de licenciatura & 3 \\
\hline Formação de professores & 3 \\
\hline \multicolumn{2}{|c|}{ Fonte: Os autores }
\end{tabular}

Nas próximas subseções será realizada a análise das duas categorias que emergiram da Análise de Conteúdo.

\subsection{Espaço do ensino nos currículos de licenciatura}

Os curso de licenciaturas, em sua maioria, são compostos de dois tipos de disciplinas: as especificas que compõe cerca de 3/4 da carga horária dos cursos e as pedagógicas que compõem 1/4. Esse modelo é chamados 3+1, desta forma ao somar o tempo total do curso os alunos cursam três anos de disciplinas especificas e um ano de disciplinas pedagógicas. Esse modelo já vem sendo modificado em algumas universidades.

Destaca-se que essa pouca carga horária destinada as disciplinas pedagógicas, de acordo com Rodrigues (2016, p. 76) pode ter como consequência "à dificuldade da articulação teoria-prática, bem como às dificuldades de entendimento dos alunos quanto ao conteúdo, aspectos que se constituem em desafio, ao professor da disciplina, em ajudar o aluno a se tornar autônomo". Os trabalhos relatam também a necessidade dessas disciplinas ofertarem conhecimentos mais práticos e voltados para a realidade da escola. Tendo um enfoque 
carregado de uma teoria distante da futura prática dos acadêmicos, essas disciplinas acabam perdendo o sentido e deixando lacunas importantes na constituição dos docentes.

Além desse aspecto, na maioria dos cursos ocorre uma desvalorização dessas disciplinas, pois muitas delas são lecionadas por professores substitutos que na maioria das vezes nunca lecionaram em uma escola da rede básica, ou seja, eles falam sobre como o futuro professor deverá fazer, sem nunca ter feito antes, e muitas vezes, a fala sem experiência é vazia de possibilidade de aplicação prática. Desta forma, os professores que tem experiência na sala de aula da educação básica ou que pensam suas aulas mentalizando a realidade dessas escolas, tem "condições mais propícias para mobilizar e questionar saberes do seu conhecimento profissional que se mostrem mais contributivos ao como ensinar intimamente articulado ao para que ensinar" (CRUZ; BORGES, 2012, p. 2148).

Rodrigues (2016, p. 76) afirma que a atuação destes profissionais sem a capacitação ideal para estas disciplinas, pode ter a ver com "a política de tanto contratar professores temporários para suprir lacunas no ensino, quanto de exigir elevada carga horária de ensino, dos docentes da instituição, o que lhes obriga a lecionar praticamente qualquer disciplina que se lhes apresente".

Salienta-se ainda que muitos docentes das universidades não tem formação suficiente para lecionar certas disciplinas, no caso da disciplina de Psicologia da Educação, de acordo com uma pesquisa realizada por Rodrigues (2016) com professores que lecionaram essas disciplinas, todos eram psicólogos, mas não eram especialistas em Psicologia Educacional/ Escolar. Dessa forma professores despreparados lecionam essas disciplinas que são muito importante para os futuros docentes, pois é necessário que os alunos dominem os conteúdos específicos da sua área, mas também é vital que o educador domine as teorias de ensino, para conseguir saber como ensinar seus alunos, identificar as dificuldades de aprendizagem e ter instrumentos para criar estratégias de ensino adequadas para cada contexto.

Um outro problema apontado na literatura, é o foco demasiado dado as teorias do desenvolvimento, em detrimento das teorias de ensino e aprendizagem propriamente ditas. Uma possível explicação para que isso aconteça é o fato de muitos dos professores destas disciplinas serem psicólogos com formação em psicologia clínica e que não conseguem direcionar os conteúdos lecionados para as necessidades da formação dos docentes (RODRIGUES, 2016).

Cruz e André (2014) afirmam que através das teorias de ensino e de aprendizagem, os futuros professores têm a capacidade de "compreender a complexidade da mediação didática, com condições de articular saberes dos conteúdos específicos com os dos conteúdos 
pedagógicos e das suas experiências" (p. 20). Porém, ainda de acordo com os autores "não se manifesta a preocupação com a especificidade do saber pedagógico, visto que não é predominante a problematização desses saberes a partir da forma como a própria aula acontece" (CRUZ; ANDRÉ, 2014, p. 20).

Desta forma, os trabalhos recuperados apontam para uma formação que acaba sendo insuficiente no que diz respeito as teorias de ensino. Disciplinas essas que são muito importantes nos cursos de licenciatura, pois são elas que dão suporte para a pratica profissional do professor, sem elas os professores apenas repetem os métodos que foram utilizados com eles, não sabendo lidar com as dificuldades que aparecem em sua sala de aula.

\subsection{Formação de professores}

Considerando os dados históricos da educação brasileira apresentados neste trabalho, resultante das avaliações externas realizadas pelo INEP, pode-se identificar a necessidade de que aconteça alguma mudança para que haja melhores resultados. Tendo em vista que neste contexto os professores são os profissionais que estão na linha de frente, diretamente envolvidos no processo de ensino e aprendizagem, podem desempenhar um papel fundamental neste sentido.

Porém, deparar-se com o insucesso do aluno, normalmente, começa-se uma busca para identificar os culpados pelo resultado negativo. Diferentemente de um diagnóstico construtivo, o que acontece é um "jogo de empurra”, no qual a família responsabiliza a escola e os professores, os professores, por sua vez, justificam a não aprendizagem ora pela negligência da família, ora pelo desinteresse do aluno, ou ainda a uma condição orgânica ou cognitiva deficitária. Outra justificativa comum é a de responsabilizar as lacunas de aprendizagem deixadas pelas etapas anteriores. E, esse tipo de argumentação, adentra os ambientes acadêmicos nos quais os docentes, muitas vezes, atribuem os altos índices de reprovação as falhas do ensino básico.

Porém, este tipo de análise da situação além de ser improdutivo, isenta os atores de suas responsabilidades, fazendo com que se perpetue este sistema capenga de ensino, com baixos índices de aprendizagem e alto número de reprovações e evasões. Tem-se clareza de que não existe apenas um culpado, um único responsável pelo fracasso escolar. Não é a intenção simplificar este problema tão complexo. Porém, acredita-se que dentre os atores envolvidos nestas relações, é do professor que se espera ter uma capacidade maior de análise das contingências envolvidas no processo de ensino e aprendizagem, e, desta análise, realizar 
as alterações necessárias em sua prática para que possa dar conta de obter melhores resultados.

Neste sentido, destacamos a importância da formação epistemológica do professor, pois é ela que instrumentaliza a sua ação em sala de aula, e, também o capacita a analisá-la de forma crítica (VERONEZ; PEREIRA, 2017). Quanto mais propriedade ele possui, tanto sobre a sua prática, quanto sobre as contingências que estão envolvidas no processo de ensino e aprendizagem, maior será a sua capacidade de adaptar suas ações de acordo com as necessidades dos alunos (BECKER, 1993).

Considerando o investimento necessário para esta capacitação do docente, seja de tempo ou de energia. Levando em conta o cenário de desvalorização da profissão docente, principalmente daqueles que atuam na rede básica de ensino, que leva ao professor ter que trabalhar mais de 40 horas semanais, com diversas turmas e um sem-número de alunos, entende-se que a formação continuada, realizada fora do horário de trabalho, acaba sendo muitas vezes inviável, ou não tão produtiva, devido ao esgotamento do profissional.

Por isso, entende-se que a formação inicial pode exercer um papel fundamental nesta instrumentalização do docente. Porém, a literatura acadêmica demonstra uma série de dificuldades presentes nos cursos de licenciatura. Segundo Araújo (2016) e Romanowski e Silva (2018), o modelo ainda predominante nas universidades dá prioridade aos conteúdos específicos em detrimento dos pedagógicos, não fornecendo ao futuro professor ferramentas importantes para lidar com as peculiaridades da sua profissão.

Veronez e Pereira (2017, p. 123) complementam este ponto de vista afirmando que os graduandos, principalmente devido a esta formação deficitária, tem sua prática docente "mais próximas de suas experiências como alunos da Educação Básica que das proporcionadas no Ensino Superior, principalmente nas disciplinas de cunho pedagógico", ou seja, os futuros professores ao invés de aprender novos métodos de ensinar seus alunos, reproduzem os métodos que foram utilizados com ele na educação básica, e desta forma nunca consegue-se sair de um ensino tecnicista e tradicional.

Para Araújo (2016), existe a necessidade de os cursos de licenciatura ofereçam aos futuros professores reflexões sobre o trabalho em sala de aula, uma formação composta por metodologias e abordagens consolidadas. Pois, para o autor, os profissionais que formados por este tipo de curso terão grande possibilidade de terem suas concepções epistemológicas e suas práticas pedagógicas modificadas, ocasionando assim possíveis impactos positivos no resultado do seu trabalho. 


\section{Considerações Finais}

Desta forma, acredita-se que, com o cenário preocupante demonstrado pelos indicadores de aproveitamento escolar resultantes das avaliações externas, o professor, como um dos principais agentes no processo de ensino e aprendizagem, pode desempenhar um papel de protagonismo na reversão deste quadro.

Tendo em vista a dificuldade encontrada para que se realize uma formação continuada de qualidade após a sua formação inicial. Considerando a desvalorização do professor de ensino básico no país, que faz o profissional, muitas vezes, ter longas jornadas de trabalho e inúmeras turmas. Os cursos de licenciaturas acabam por ser um espaço vital na formação destes docentes, tendo um impacto importante na qualidade do seu futuro desempenho profissional.

Neste sentido, entende-se que se faz necessário que seja dada uma atenção maior, seja na qualificação dos profissionais que as ministram, na adequação e contextualização de disciplinas como Psicologia da Educação para as necessidades dos futuros docentes, ou mesmo no tempo dedicado a elas nos currículos das licenciaturas. Pois são estas disciplinas que instrumentalizam o professor, capacitando-o tanto para que ele possa ter recursos que lhe permitam ter propriedade sobre a sua prática, quanto que lhe permita depreender do seu dia-adia na sala de aula as necessidades dos seus alunos.

\section{Referências}

ARAÚJO, M. S. Reflexões e desafios na formação de professores de línguas estrangeira. Revista L@el em (dis-)curso, v. 8, p.39-54, 2016. Disponível em: https://revistas.pucsp.br/revlael/article/view/29644/22984. Acesso em: 02 set. 2018.

BARDIN, L. Análise de Conteúdo. São Paulo: Edições 70, 2011.

BECKER, F. Modelos pedagógicos e modelos epistemológicos. Porto Alegre, 1993 18-23.

CRUZ, G. B.; ANDRÉ, M. E. D. A. Ensino de didática: um estudo sobre concepções e práticas de professores formadores. Educação em Revista, Belo Horizonte, v. 30, n. 4, p.1-24, 2014. Disponível em: http://www.scielo.br/pdf/edur/v30n4/09.pdf. Acesso em: 16 out. 2018.

CRUZ, G. B.; BORGES, L. P. C. O ensino de didática em cursos de licenciatura na perspectiva do professor formador. In: Encontro Nacional de Didática e Práticas de Ensino (XVI ENDIPE), 2012, Campinas. Livro 2. Campinas: Junqueira\&marin Editores, 2012. p. 213622149.2 Disponível em: http://www.infoteca.inf.br/endipe/smarty/templates/arquivos_template/upload_arquivos/acerv o/docs/2154b.pdf. Acesso em: 12 out. 2018. 
Fundação Lemann e Meritt (2018): portal QEdu.org.br, acessado em 16/2018/2018.

INSTITUTO NACIONAL DE ESTUDOS E PESQUISAS EDUCACIONAIS ANÍSIO TEIXEIRA. Prova Brasil 2015. Brasília: Inep, 2015.

RODRIGUES, M. E. Educational Psychology: Perceptions of Professors in Education Courses. Revista Psicologia da Educação, [s.1.], n. 43, p.69-79, 2016. GN1 Genesis Network. http://dx.doi.org/10.5935/2175-3520.20160007. Disponível em: http://pepsic.bvsalud.org/pdf/psie/n43/n43a07.pdf. Acesso em: 12 out. 2018.

ROMANOWSKI, J. P.; SILVA, P. J. A formação pedagógica no curso de licenciatura em física: articulação entre os campos do conhecimento. Ensaio Pesquisa em Educação em Ciências (Belo Horizonte), [s.1.], v. 20, p.1-24, 16 jul. 2018. FapUNIFESP (SciELO). http://dx.doi.org/10.1590/1983-211720182001019. Disponível em: http://www.scielo.br/pdf/epec/v20/1983-2117-epec-20-e9270.pdf. Acesso em: 03 set. 2018.

VERONEZ, M. R. D; PEREIRA, E. Os dizeres dos alunos de um curso de licenciatura em matemática. Educação Matemática em Revista - RS. v. 1, n. 18, p.113-125, 2017. Disponível em: http://sbemrs.org/revista/index.php/2011_1/article/view/264. Acesso em: 12 out. 2018. 